\title{
Economic Feasibility of Converting from a Bare Ground System with Seepage Irrigation to Plasticulture for Cabbage Production: Where is the Risk?
}

\author{
Charles E. Barrett \\ Institute of Food and Agricultural Sciences, University of Florida, \\ IFAS-Extension, Live Oak, FL 32060; and Horticultural Sciences \\ Department, Institute of Food and Agricultural Sciences, University of \\ Florida, Gainesville, FL 32611
}

Lincoln Zotarelli ${ }^{1}$, Lucas G. Paranhos, and Peter Dittmar Horticultural Sciences Department, Institute of Food and Agricultural Sciences, University of Florida, Gainesville, FL 32611

Clyde W. Fraisse

Agricultural and Biological Engineering Department, Institute of Food and Agricultural Sciences, University of Florida, Gainesville, FL 32611

John VanSickle

Food and Resource Economics Department, Institute of Food and Agricultural Sciences, University of Florida, Gainesville, FL 32611

Additional index words. cabbage, Brassica oleracea var. capitata, drip irrigation, plastic mulch, simulation, stochastic, risk-aversion coefficient, weather

\begin{abstract}
Weather has a major influence on cabbage (Brassica oleracea var. capitata $\mathbf{L}$.) production. Variation in yield between years and cropping seasons is common in North America. Cabbage in Florida has historically been cultivated on bare ground with seepage irrigation. The objectives of this study were to compare yield and profit of a bare ground cabbage production system used in Florida with an alternative plasticulture system. Data from various cabbage trials were combined by production system and used to create regression equations that predicted yield based on air temperature and solar radiation that were significantly correlated with yield. The regression equations were then simulated with correlated stochastic air temperature and solar radiation to estimate the yield distributions for both systems. Cabbage price (\$/Mg fresh) was stochastically simulated (correlated to yield) to be used in the profit model. The profit model was created by using the product of yield and the price per unit yield minus fixed and variable costs associated with production and marketing. Simulated profit for bare ground and plasticulture was used to estimate their respective distributions to provide a tool for making better management decisions in the presence of risky weather conditions. The plasticulture system was estimated to have a $36 \%$ higher cost but a 57\% higher profit than the bare ground system. This is, in large part, because the simulated mean yield for the bare ground system was $29.7 \mathrm{Mg} \cdot \mathrm{ha}^{-1}$ compared with 54.4 $\mathrm{Mg} \cdot \mathrm{ha}^{-1}$ for plasticulture. These findings confirmed that plasticulture is an economically viable best management practice for cabbage production in Northeast Florida.
\end{abstract}

Florida is a top producer of cabbage in the United States with an annual average value close to $\$ 50$ million (FDACS, 2014). Most of

Received for publication 6 Feb. 2018. Accepted for publication 6 Apr. 2018.

This research was supported by the Florida Specialty Crop Block Grant Program (Contract \#00085482) and the University of Florida Office of the Dean of Extension, 2011-12 Extension Program Enhancement Grant.

We are grateful for the contribution and support of Northeast Florida vegetable growers, especially Tommy Miller and Mark Barnes.

${ }^{1}$ Corresponding author. E-mail: lzota@ufl.edu. the cabbage produced in the state is grown in a bare ground system using seepage irrigation. Seepage is a method of irrigation that relies on large volumes of water (Dukes et al., 2010) and often a shallow semi-impermeable soil layer. In a seepage system, the water table is perched on top of the semi-impermeable soil layer and raised to the crop root zone. This type of irrigation system requires the subsurface layers of soil to be saturated (Locascio, 2005; Sato et al., 2009), thereby reducing the capability of the soil to store water during rainfall events. Adding to the challenges of this type of irrigation system are the spatial variations of soil characteristics and the spatial and temporal variability in rainfall. These heterogeneous distributions of rainfall and soil characteristics reduce crop uniformity and yield and increase the potential for off-site movement of water soluble nutrients from leaching and runoff.

Florida cabbage producers capture high market prices by growing during winter months when production in most other states is limited (Strandberg and White, 1979). Because the cabbage planting season in Northeast Florida typically begins in early September and can finish as late as midJanuary, a wide range of weather conditions are commonly experienced for any given planting date (Paranhos et al., 2016b). Producing during these months puts growers at risk of severe weather events from hurricanes at the beginning of the season and freezes as the season progresses. National and Florida state average marketable yields are relatively stable at around $40 \mathrm{Mg} \cdot \mathrm{ha}^{-1}$, but these averages do not reflect the actual variability across fields seen in Northeast Florida (Fig. 1). Likewise, the national average price is much less variable than the average price received in Florida (Fig. 2)

Weather during the growing season is a major driver of cabbage yield. As a result, differences in yield are expected between years and even planting dates within the same year. Barrett et al. (2015) reported 34\% and $42 \%$ reductions in yield in 2011-12 for cabbage planted in October and December, respectively, when compared with the yield in previous year planted in December. The warmer air temperatures in the 2011-12 growing seasons led to reduction of cabbage yield. Reduced yield was reported in the warmer 2005 season when compared with the cooler 2003 and 2004 seasons in Ontario, Canada (McKeown et al., 2010). In fact, differences in cabbage yield and head characteristics related to planting date, geographic location, and weather have been reported extensively in the literature (Chipman and Thorpe, 1979; de Moel and Everaarts, 1990; Greenland et al., 2000; Kleinhenz and Wszelaki, 2003; McKeown et al., 2010; Orzolek, 1996; Radovich et al., 2004; Sundstrom and Story, 1984; Warland et al., 2006; Wszelaki and Kleinhenz, 2003). Air temperature is often cited as a contributing factor to yield differences, and cabbage growth has been reported to be optimized between 15 and $21{ }^{\circ} \mathrm{C}$ (Boswell and Jones, 1941; Criddle et al., 1997; Hara and Sonoda, 1982).

Although various aspects of Florida cabbage production have been studied in Florida for more than 50 years (Csizinszky, 1987; Csizinszky and Schuster, 1985, 1993; Csizinszky and Stanley, 1984; Forbes et al., 1984; Halsey et al., 1996; Hochmuth et al., 1993; Howe and Waters, 1994; Stoffella and Fleming, 1990; Strandberg and White, 1979; White and Forbes, 1976), none have sought to identify and quantify the impacts of weather on both yield and profit. With the ongoing reform of agricultural best management practices, recent droughts, growth in state population, climate change uncertainties, and 


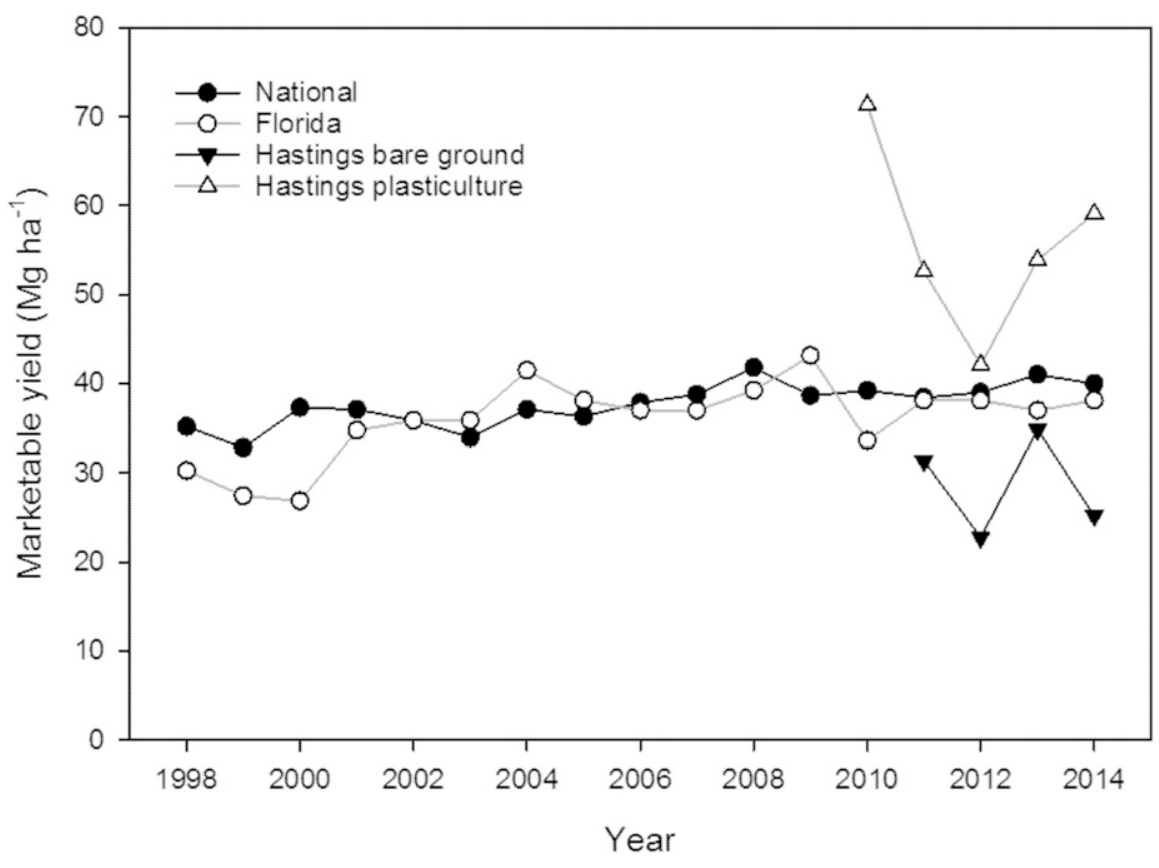

Fig. 1. National, Florida, and Hastings bare ground and plasticulture average cabbage marketable yields (Mg.ha- ${ }^{-1}$ ) from 1998 to 2014.

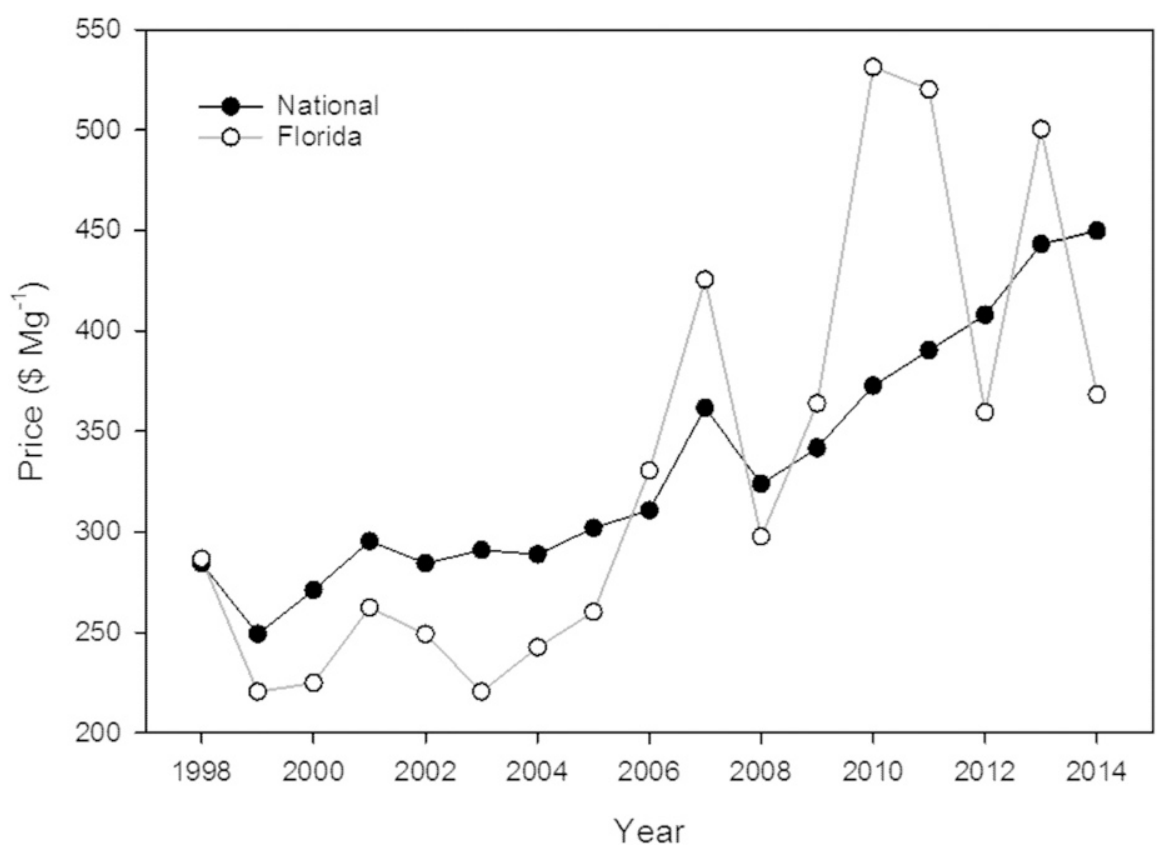

Fig. 2. National and Florida average cabbage prices $(\$ / M g)$ from 1998 to 2014. Data sourced from U.S. Department of Agriculture (2015).

saltwater intrusion, demand for improved crop management systems that can increase production, conserve water, and reduce the potential for nutrient loss has emerged. Furthermore, increases in costs and demand for agricultural inputs have highlighted the need to develop production systems that increase input use efficiency (Cordell et al., 2009; Marella, 2014).

The combination of plastic mulch, drip irrigation, an increased plant population compared with the seepage system, and the ability to apply fertilizer through the irrigation system (fertigation) defines the plasticulture accepted by commercial growers in Florida. This could be, in part, because no research has been performed to assess the economic feasibility of a plasticulture system adapted for use in Florida. Moreover, the low cost of operation and ease of use associated with the bare ground system (Locascio, 2005) have not provided the necessary incentives to drive the adoption of a commercial plasticulture cabbage system.

Barrett et al. (2015, 2018) developed a drip-irrigated plasticulture system and nitrogen fertilizer rates to increase water and fertilizer use efficiencies while increasing plant population. In two follow up studies, Paranhos et al. (2016a, 2016b) examined the effects of planting date on plasticulture grown cabbage over the course of the entire Northeast Florida cabbage planting season and compared the profitability of cabbage grown using plasticulture and bare ground. The objectives of this study were to compare yield and profit of the current bare ground cabbage production system used in Florida with the plasticulture system proposed in Barrett et al. (2015) by using a model with stochastically simulated independent variables that are known to be correlated with yield. It was hypothesized that these models can predict yield based on specific weather parameters to assess the economic risk in cabbage production systems in terms of yield and profit and be used as a decision support tool for growers.

\section{Materials and Methods}

\section{Cabbage production trials}

Plasticulture trials. Cabbage yield data were collected from field experiments conducted at the University of Florida, Institute of Food and Agricultural Sciences, Hastings Agricultural Extension Center in Hastings, FL. The plasticulture trials consisted of cabbage grown on 1.2-m-wide raised beds with black plastic mulch $(1.8 \mathrm{~m}$ width, $1.25 \mathrm{~mm}$ thickness, VIF film; Polygro, LLC, Safety Harbor, FL) and two drip tapes (Aqua-Traxx model EA5081222, $16 \mathrm{~mm}$ diameter, $0.3 \mathrm{~m}$ emitter spacing, $0.5 \mathrm{~L} \cdot \mathrm{h}^{-1}$ at $55 \mathrm{kPa}$; Toro Agricultural Irrigation, El Cajon, CA). Beds were spaced $2.0 \mathrm{~m}$ on center.

The 2010-12 plasticulture trials were designed to determine the optimum in-row plant spacing and number of rows for cabbage grown using plastic mulch and drip irrigation (population trials). In-row plant spacings of $15,20,25,30$, and $35 \mathrm{~cm}$ and a 3-row or 4-row configuration were combined to make 10 spacing vs. row configuration treatments (Barrett et al., 2015). A 3-row or 4-row configuration with an in-row plant spacing of 25-35 $\mathrm{cm}$ was found to optimize crop yield; therefore, only these data were used in the current analysis. The 2012-14 nitrogen fertilizer rate trials were conducted to determine the optimum nitrogen rate for cabbage grown in the newly developed plasticulture system (Barrett et al., 2018). Nitrogen rates ranged from 90 to $672 \mathrm{~kg} \cdot \mathrm{ha}^{-1}$ for the highest recommended population from 
the population trials $(77,500$ plants/ha). The 2013-15 planting date trials tested the recommended population range (4-row configuration 55,357-77,500 plants/ha) from the population trials at four planting dates (Paranhos et al., 2016b). The planting dates covered nearly the entire plating season for cabbage in Northeast Florida, from September to December. The objective of the planting date trial was to determine the optimum plant population for various planting dates throughout the season.

Bare ground trials. The bare ground trials followed north Florida grower standards for cole crops using seepage irrigation. In this system, plants are grown at a plat population of 48,438 plants/acre with an in-row plant spacing between 20 and $24 \mathrm{~cm}$ with a row spacing of $1-1.1 \mathrm{~m}$. There are typically 16 rows per bed and between beds is a furrow. Furrows are used for irrigation, and in the event of excess rainfall, they provide drainage. The bare ground trial data were collected from trials that tested fungicide and herbicide efficacy. The 2011-13 fungicide trials examined recommended fungicides and new fungicides that are currently under development for use in cabbage. The 2013-14 herbicide timing trials examined the effect of different application timings of oxyfluorfen at a rate of $0.21 \mathrm{~kg} \cdot \mathrm{ha}^{-1}$.

\section{Development of the models}

The impacts of weather on the variability in yield seen between various cabbage trials in Northeast Florida were analyzed using correlation analyses to determine which weather parameters had the greatest effect on yield. Data were combined by production system and used to create regression equations that predicted yield based on weather parameters that were significantly $(P<0.01)$ correlated with yield. The regression equations were then simulated with selected stochastic weather variables to estimate the yield distributions for the standard bare ground practice and the alternative plasticulture system. Next, price (\$/Mg fresh cabbage) was stochastically simulated to calculate revenue for the profit model. The profit model was created by using the product of yield and the price per unit yield minus fixed and variable costs associated with production and marketing following Paranhos et al. (2016a). Finally, profit was simulated for the two production strategies (bare ground and plasticulture) to estimate their respective distributions and provide a tool for making better management decisions in the presence of risky weather conditions.

The data used in these analyses were collected over the course of 5 years, including six plasticulture trials covering 13 planting dates and four bare ground trials covering four planting dates. Although these data were gathered from trials testing various plant populations, nitrogen fertilizer rates, planting dates, and fungicide and herbicide timing, only data representing the current grower standard or recommended plasticulture and bare ground practices were used in this analysis. The results of all studies are summarized in Table 1.

\section{Yield model}

Weather data on cumulative rainfall and daily averages from planting to harvest for minimum air temperature, maximum air temperature, solar radiation, and evapotranspiration were collected from the Hastings (FL) weather station of the Florida Automated Weather Network. A matrix of Pearson correlations was used to identify weather parameters that were significantly correlated with marketable yield and price. Pearson correlations and regression analyses were completed using the CORR and REG procedures in SAS version 9.4 (SAS Institute, Cary, NC). The selected multiple regression yield models are described as follows:

$$
\begin{aligned}
\text { Plasticulture: Yield }= & \text { intercept } \\
& +\left(B_{\text {solrad }} \times \text { solrad }\right) \\
& +\left(B_{\text {temp }} \times \text { temp }\right) \\
& +\left(B_{\text {pop }} \times \text { pop }\right)+\varepsilon
\end{aligned}
$$

Bareground: Yield $=$ intercept

$$
\begin{aligned}
& +\left(B_{\text {solrad }} \times \text { solrad }\right) \\
& +\left(B_{\text {temp }} \times \text { temp }\right)+\varepsilon
\end{aligned}
$$

where Yield $=$ marketable yield $\mathrm{Mg} \cdot \mathrm{ha}^{-1}$; intercept $=$ the $y$-intercept as estimated by the regression model; $\beta_{\text {solrad }}=$ the solar radiation parameter estimated from the regression model; solrad = growing season average daily solar radiation $\mathrm{MJ} \cdot \mathrm{m}^{-2} \cdot \mathrm{d}^{-1}$; $\beta_{\text {temp }}=$ the average daily air temperature parameter estimate from the regression model; temp = growing season average daily air temperature $\left({ }^{\circ} \mathrm{C}\right) ; \beta_{\text {pop }}=$ the population parameter estimate from the regression model; pop $=$ population, the mean 65,813 plants $/$ ha of the three recommended populations for plasticulture was used as a constant for the analyses; and $\varepsilon=$ the residual or error from the regression trend line. The population for the bare ground trials was constant at 48,438 plants/ha and was therefore not estimated in the bare ground regression model.

The multiple regression model for plasticulture was statistically significant $(P \leq 0.001)$ with an adjusted $R^{2}$ value of 0.33 . The multiple regression model for bare ground was statistically significant $(P \leq 0.001)$ with an adjusted $R^{2}$ value of 0.21 . These relatively low $R^{2}$ values predict a meaningful portion of the variation in yield seen in these two cabbage production systems using average solar radiation and air temperature and suggest there are many other factors that also affect yield.

The multiple regression models for stochastic simulation became:

$$
\begin{aligned}
\text { Plasticulture }: \text { Yield }= & -14.25 \\
& +(6.18 \times \text { solrad }) \\
& +(2.60 \times \text { temp }) \\
& +(-0.01 \times 65,813)+\varepsilon
\end{aligned}
$$

Bare ground: Yield $=29.68$

$$
\begin{aligned}
& +(-1.94 \times \text { solrad }) \\
& +(1.38 \times \text { temp })+\varepsilon
\end{aligned}
$$

\section{Stochastic simulation of the yield regression models}

The plasticulture and bare ground multiple regression models were simulated using the multivariate empirical distribution (MVEMP) function in Simetar $^{\odot}$ software following Richardson (2001) and Richardson et al. (2000). With the MVEMP function, the inde-

\begin{tabular}{|c|c|c|c|c|}
\hline & & Mean marketable yield & $\mathrm{SD}$ & Median marketable yield \\
\hline Trial & Season & & $\mathrm{Mg} \cdot \mathrm{ha}^{-1}$ & \\
\hline Population year 1 & $2010-11$ & 71.3 & 7.2 & 71.8 \\
\hline N-rate year 2 & 2013-14 & 29.7 & 7.8 & 29.2 \\
\hline Plant date year 1 & 2013-14 & 53.9 & 10.8 & 54.7 \\
\hline Plant date year 2 & $2014-15$ & 59.1 & 13.6 & 60.1 \\
\hline Fungicide year 1 & 2011-12 & 31.4 & 3.7 & 31.4 \\
\hline Fungicide year 2 & $2012-13$ & 22.8 & 4.5 & 22.9 \\
\hline Herbicide timing year 1 & 2013-14 & 34.8 & 3.9 & 35.1 \\
\hline Herbicide timing year 2 & 2014-14 & 25.3 & 7.1 & 25.0 \\
\hline Average & & 29.6 & 4.8 & 30.2 \\
\hline
\end{tabular}
pendent variables from the regression models were made stochastic based on the sorted residuals from the deterministic component (means). Using the sorted residuals from the means, a correlation matrix was formed and by inverse transformation, correlated uniform standard deviates (CUSDs) were created to simulate values for the independent variables in both

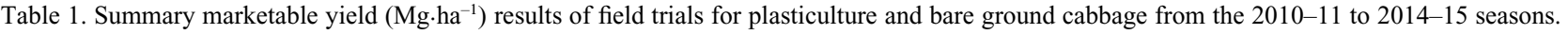


regression models. CUSDs were used to generate random values of solar radiation and air temperature because they are independent but correlated. These correlated random values were iterated simultaneously in the regression model and both regression models were simulated 500 times. Weather parameter data were tested for normality and found not to be normally distributed; therefore, truncated empirical distributions were used to reflect weather conditions typical for Florida during the cabbage growing season. Seasonal averages for weather parameters were created by taking the mean of daily observations from each growing season. The truncated empirical distributions used for all weather parameters were described as:

$$
\begin{aligned}
= & \text { TEMPIRICAL }(\text { Sorted Xis, Sorted P(Xis), } \\
& \times \text { Min, Max, CUSD })
\end{aligned}
$$

where Sorted Xi's = the sorted residual from the mean for each weather parameter for all plasticulture or bare ground trials; Sorted $\mathrm{P}(\mathrm{Xi}$ 's $)=$ the sorted probability of each residual for each weather parameter for all plastic or bare ground trials; $\mathrm{Min}=$ the minimum value for each weather parameter (seasonal average) observed for all plasticulture or bare ground trials; $M a x=$ the maximum value for each weather parameter (seasonal average) observed for all plasticulture or bare ground trials; and CUSD calculated from the yield, weather, and price correlation matrix.

The residuals for both yield regression models were simulated using the MVNORM function and was described as:

$$
\begin{aligned}
= & \text { MVNORM }(\text { Means, Covariance Matrix, } \\
& \times \text { Normal Devs })
\end{aligned}
$$

where Means $=$ expected values from the regression model; Covariance Matrix = matrix of covariances for the parameters in the regression analysis; and Normal Devs $=$ a vector of standard normal deviates.

\section{Price model}

Price was stochastically simulated and correlated with yield and weather. All price data were calculated from average Florida prices (U.S. Department of Agriculture, 2015) for the 5 years of trials (2010-14). The truncated empirical distribution used to simulate price was described as:

\section{$=$ TEMPIRICAL $($ Sorted Xis, Sorted P(Xis), $\times$ Min, Max, CUSD)}

where Sorted Xi's = the sorted residual from the mean price from 2010 to 2014; Sorted P (Xi's) = the sorted probability of each residual; Min $=$ the minimum average Florida state price received from 2010 to 2014; Max = the maximum average Florida state price received from 2010 to 2014; and CUSD calculated from the yield, weather, and price correlation matrix.

\section{Cost}

Recent budget estimates were available from Paranhos et al. (2016a). The bare ground budget was updated from VanSickle (2008) to reflect
2015 prices for fertilizer, transplants, and fumigation costs. The plasticulture budget was created by estimating the minimum capital investment to convert to plasticulture and other additional preharvest costs. The additional costs were primarily the result of the initial investment cost for a basic pumping system, required labor, plastic mulch, drip tape, irrigation fittings and supply pipes, and the increase in transplants associated with the expected $25 \%$ increase in plant population. Paranhos et al. (2016a) stated that these estimates are provided as a baseline, and because of differences among farms, actual costs could be lower or higher based on preexisting farm infrastructure or lack thereof. Harvest and marketing costs were estimated based on current data (Paranhos et al., 2016a) and added to these preharvest costs to obtain a total production cost estimate. The preharvest, fixed cost estimates were \$7501/ha (\$3036/acre) and 11,680/ha (\$4726/acre) for standard bare ground and median-recommended plasticulture plant populations, respectively. The variable harvest and marketing costs were estimated at $\$ 3.70$ for each $45 \mathrm{~kg}$ unit harvested. Total cost was estimated for mean yield at $\$ 12,302 /$ ha (\$4978/acre) for bare ground and \$20,320/ha (\$8223/acre) for plasticulture.

\section{Profit model}

Weather, yield, and price vary; therefore, bare ground and plasticulture production systems produce distinct profit distributions when their respective costs are removed. By defining the difference between bare ground and plasticulture distributions, any benefits from the plasticulture system can then be identified. The profit model was described as:

$$
\widetilde{\text { profit }}=(\widetilde{\text { yield }} \times \widetilde{\text { price }})-\text { cost }
$$

where variables under a tilde are stochastic and yield $=$ multiple regression model with stochastic weather parameters (independent variables) simulated by a MVEMP; price = stochastic Florida price from the National Agricultural Statistics Service (U.S. Department of Agriculture, 2015) for the years of the trials correlated to the yields for the plasticulture and bare ground trials; and cost = estimated total costs from Paranhos et al. (2016a) for Florida plasticulture and bare ground production systems. The profit distribution was estimated using a MVEMP.

\section{Ranking the risky alternatives}

The probability of a positive vs. a negative outcome must be assessed with an understanding of the preference the decisionmaker has for the possible outcomes (Hardaker et al., 2004). The level of risk aversion of the decision-maker must be considered to determine if cost or risk is a bigger driver of the decision to use bare ground over plasticulture. Following Hardaker et al. (2004), the bare ground and plasticulture systems were ranked based on risk by incorporating certainty equivalents, or the amount of money the decision-maker would prefer to accept in exchange for making a risky decision, and a range of risk preferences.

\section{Results and Discussion}

The stochastically simulated cabbage yields for the bare ground and plasticulture production systems based on the yield regression equation are presented in Fig. 3 as probability density functions (PDFs). The yield PDF for the plasticulture system was to the right when compared with the bare ground PDF. The implication of this difference among PDFs is that cabbage yield under plasticulture production tends to be higher under any combination of entire growing

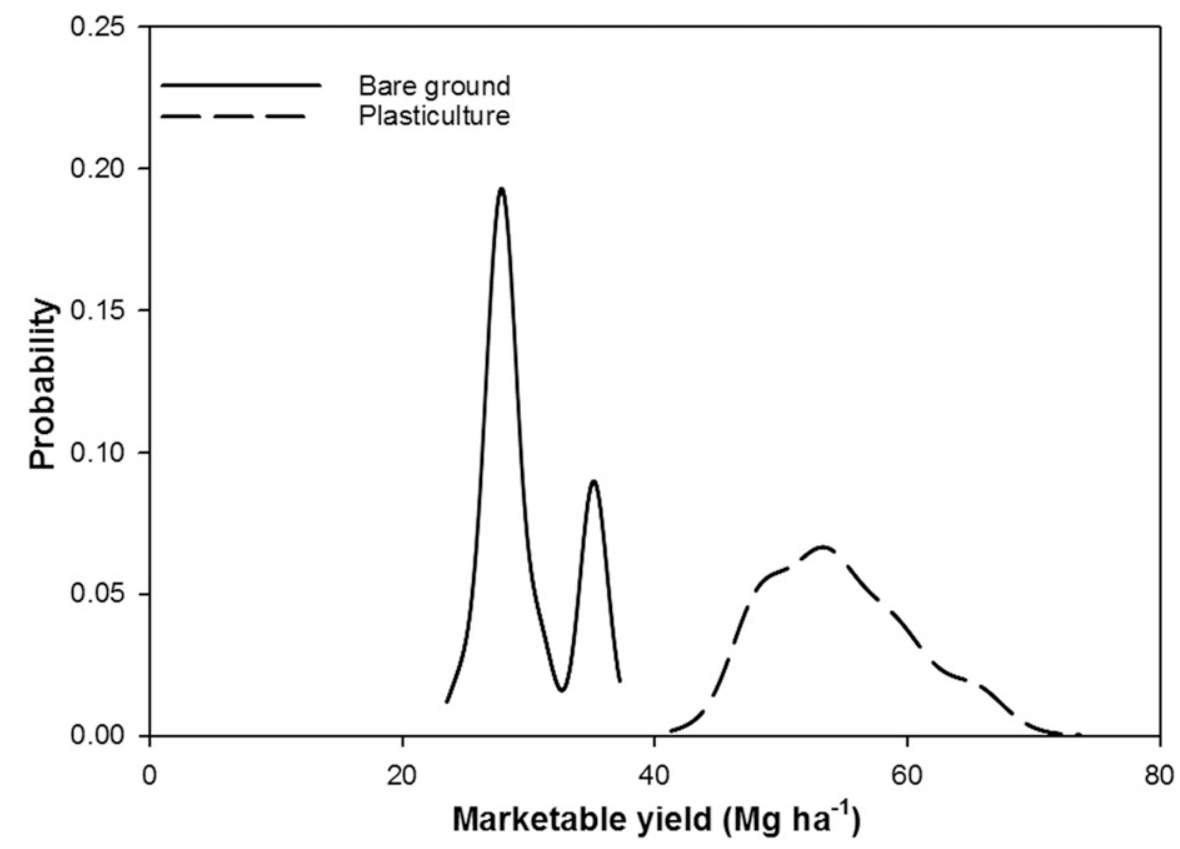

Fig. 3. Probability density functions from the stochastic simulation of cabbage yield $\left(\mathrm{Mg} \cdot \mathrm{ha}^{-1}\right)$ for the bare ground and plasticulture production systems including risky weather conditions in Northeast Florida. 
Table 2. Summary statistics for the stochastically simulated profit models for plasticulture and bare ground cabbage production systems.

\begin{tabular}{|c|c|c|c|c|c|c|}
\hline & Mean yield $\left(\mathrm{Mg} \cdot \mathrm{ha}^{-1}\right)$ & SD & $\mathrm{CV}$ & Mean profit $(\$ /$ ha $)$ & SD & $\mathrm{CV}$ \\
\hline Plasticulture & 54.4 & 5.7 & 10.6 & $\$ 8,540$ & $\$ 4,427$ & 52 \\
\hline Bare ground & 29.7 & 3.4 & 11.6 & $\$ 3,700$ & $\$ 2,779$ & 75 \\
\hline
\end{tabular}

season average air temperature and solar radiation. The SD was lower for the simulated yield of the bare ground production system (Table 2), indicating a reduced variability in trial data as compared with the plasticulture system. However, the CV was 10.6 for plasticulture and 11.6 for bare ground which, in relation to the mean, suggests that the variability in yield of the plasticulture system is smaller than the variability in yield for the bare ground system. The simulated mean yield for bare ground was $29.7 \mathrm{Mg} \cdot \mathrm{ha}^{-1}$, whereas the plasticulture mean yield was $54.4 \mathrm{Mg} \cdot \mathrm{ha}^{-1}$. This represents an 83\% (24.7 $\mathrm{Mg} \cdot \mathrm{ha}^{-1}$ ) increase in marketable yield for plasticulture when compared with the conventional bare ground system.

The differences in the shapes of the PDFs between the two systems indicate the limitations of the reduced data set for the bare ground system as compared with the plasticulture system and depict the yield variability seen in both systems. The bimodal distribution in yield seen for the bare ground system would be expected to become more continuous and likely more broad (increased SD) as more data points are added to the analysis. This may be because the planting dates of the bare ground trials were between November and January, representing only a portion of the growing season. This is a limitation of the available data for bare ground system. The greater variation seen in the plasticulture PDF could be explained as an effect of this data set representing most of the Northeast Florida growing season from September to December and the wide range of weather conditions experienced during that timeframe.

The larger SD and ranges in yield for plasticulture are expected to decrease as growers improve their crop management and mastery of the plasticulture system over time. Benefits of the bare ground system are the ease of operation and low-cost maintenance which have led to a long history of use (Locascio, 2005). If adoption of the plasticulture system is increased, the PDF for plasticulture is expected to shift further to the right and become narrower (Fig. 3), that is, yield is expected to stabilize at a higher mean with a lower SD as grower adoption increases and management of the system is optimized.

In comparison, the simulation of yield for both systems based primarily on the deviations from the mean results in an incomplete and misleading visualization of the risks associated with yield from year to year, because in this case, weather effects are neglected. Figure 4 shows the simulation of cabbage yield for both systems including the effect of weather on cabbage yield. The similarities between the two simulations for the plasticulture system suggest that the

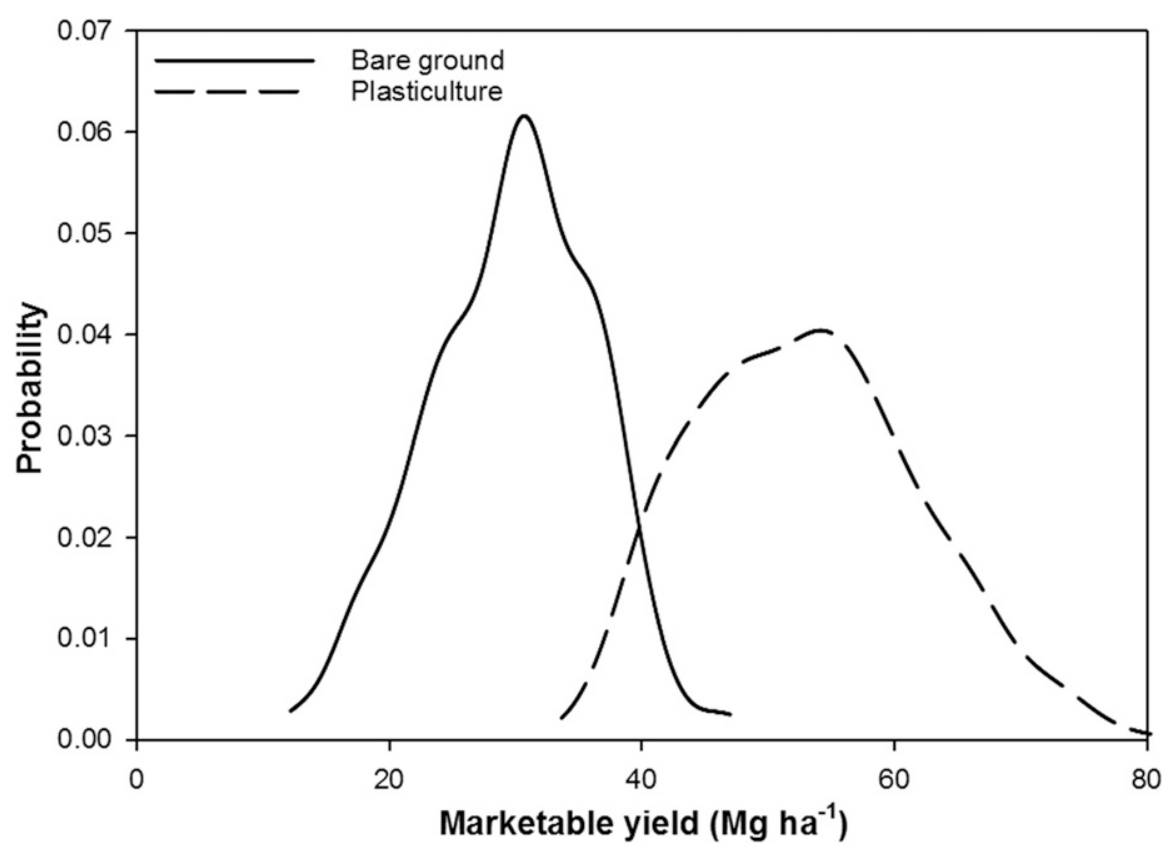

Fig. 4. Probability density functions of the simulated deterministic mean cabbage yield $\left(\mathrm{Mg} \cdot \mathrm{ha}^{-1}\right)$ for the bare ground and plasticulture production systems.

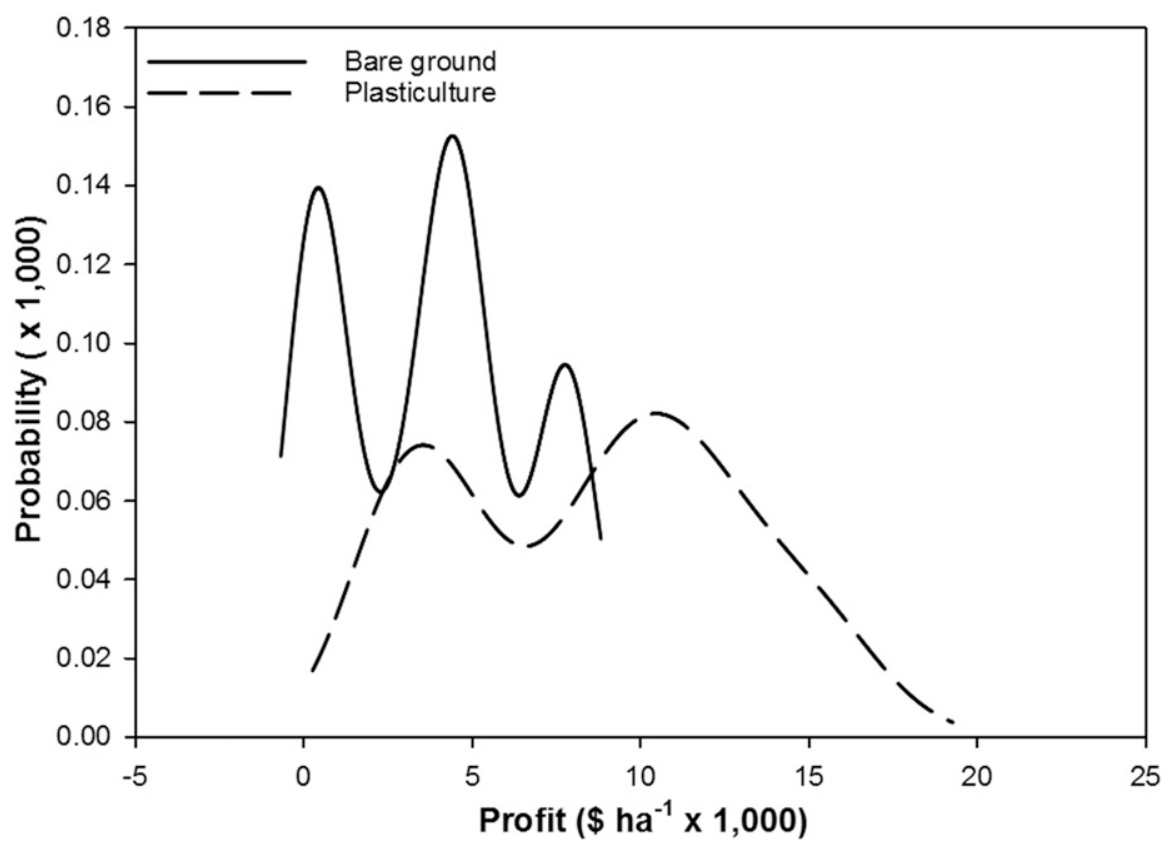

Fig. 5. Probability density functions from the stochastic simulation of bare ground and plasticulture cabbage production system profit on a hectare basis.

plasticulture system is less affected by weather as compared with the bare ground system. This was expected because one of the benefits of plasticulture is the potential to mitigate the environmental effects of weather on yield (Lament, 1993; Wittwer, 1993).
The simulations of the profit model for the bare ground and plasticulture systems reflect the variability seen in the yield simulations. Figure 5 provides a visual representation of the profit model PDFs and the monetary risk associated with deciding to produce cabbage using a bare ground or plasticulture system 
after incorporating costs and prices received. The profit model is structured such that a profit of zero dollars would be the break-even point (Fig. 5). The profit PDFs show that there is a lower probability of receiving a loss with the plasticulture system when compared with the bare ground system. Similar to the yield PDFs, the mean profit for the plasticulture system lies to the right (Fig. 5), indicating that under most combinations of average air temperature and solar radiation, cabbage grown on plasticulture will result in higher profit compared with that in bare ground. These profit comparisons are encouraging for the adoption of plasticulture because although the plasticulture system profit was calculated using a $36 \%$ higher fixed cost (\$11,679/ha compared with $\$ 7501 /$ ha for bare ground), the mean profit for plasticulture was $57 \%$ higher, $\$ 8540 /$ ha, compared with $\$ 3700 /$ ha for bare ground (Table 2). These profit simulations also suggest that the decision to use bare ground over plasticulture may be driven more by the higher initial cost or the perceived risk associated with plasticulture use.

Management decisions are often driven by financial incentives, and in Northeast Florida, the cost of water is low, which reduces the incentive to use plasticulture. In the western United States, more research has been conducted on irrigation technology adoption (Carey and Zilberman, 2002; Caswell et al., 1990) probably as a result of the acute water scarcity faced by those states. As Carey and Zilberman (2002) point out with their real options model, "a farm will not invest in modern technology until the expected present value of investment exceeds the cost by a potentially large hurdle rate." This is because large-scale irrigation investments can be irreversible and there is uncertainty associated with the technology. One potential strategy to overcome these barriers in Florida would be to start with a small investment and test the technology on a small scale. Barrett et al. (2014) demonstrated a low-cost approach to converting from a bare ground system to a plasticulture system on a small scale.

Although the yield and profit PDFs from the present study suggest that the decision to choose bare ground over plasticulture could primarily be driven by the larger initial cost of the plasticulture system, stochastic dominance with respect to a function (SDRF) and stochastic efficiency with respect to a function (SERF) analyses were used to rank the two production systems based on a range of risk-aversion coefficients (RACs). RACs make it possible to compare a set of risky alternatives across a range of risk preferences by setting a low and high risk-aversion limit. A lower RAC of 0 was used for the riskneutral decision-maker and an upper RAC of 0.0007 (risk averse) was used based on calculations suggested by Hardaker et al. (2004) wherein the authors adapt relative risk aversion proposed by Anderson and Dillon (1992). By substituting the combined average profit of our two scenarios for wealth, we were able to compare the two production systems across this range of risk preferences. The SDRF rankings for both the risk-neutral and risk-averse decision-maker confirm the results for the PDFs for yield and profit, suggesting that plasticulture is more preferred (Table 3). The SERF analysis gives a graphical representation of plasticulture and bare ground certainty equivalents over the range of RACs from risk neutral to risk averse (Fig. 6). Similar to the SDRF analysis, plasticulture dominates bare ground at all absolute RACs. Therefore, both the risk-averse and risk-neutral decision-maker should prefer plasticulture over bare ground. Figure 6 shows the risk premium chart representing the amount a risk-averse decision-maker would pay to change from bare ground to plasticulture. The extremely risk-averse decision-maker (RAC 0.0007) would pay \$2627/ha, whereas the more risk-neutral producer (RAC 0.0002) would pay $\$ 3750 /$ ha to switch from bare ground to plasticulture.

From the results of the present study, we are unable to determine why growers choose bare ground over plasticulture, but it is very likely that this decision is largely based on the higher cost of the plasticulture system and the ease of use of the bare ground system. There is also a familiarity with the bare ground system that stems from decades of use. Finally, double cropping in the plasticulture

system could allow for the depreciation of initial costs over multiple crops, thereby reducing the cost associated with an individual crop and making plasticulture more attractive to undecided growers.

\section{Conclusions}

Incorporating weather-related risk into yield prediction models can help the vegetable growers to decide between alternative production systems, given uncertain weather during the growing season. Regression models were simulated stochastically to predict cabbage yield and profit under uncertain weather conditions. Cabbage grown under plasticulture produced $24.7 \mathrm{Mg} \cdot \mathrm{ha}^{-1}$ higher mean yield and $\$ 4840 /$ ha more profit as compared with bare ground, confirming its potential for commercial use in Northeast Florida. Future research should examine grower preferences between plasticulture and bare ground to learn more about the barriers to adoption for this agricultural technology. The results suggest that extension education has a role in making more producers aware of the advantages plasticulture has over bare ground production. As climate predictions continue to get more accurate, patterns such as El Niño and La Niña should be examined for their effects on crop yield and profit.

Table 3. Analysis of profit with a plasticulture or bare ground cabbage production system using stochastic dominance with respect to a function (SDRF).

\begin{tabular}{lccc}
\hline & \multicolumn{2}{c}{ Efficient set based on SDRF } \\
\hline & Lower RAC $=0$ & \multicolumn{2}{c}{ Upper RAC $=0.0007$} \\
\cline { 4 - 4 } & Level of preference & & Level of preference \\
\hline Plasticulture & Most preferred & Plasticulture & Most preferred \\
Bare ground & Second most preferred & Bare ground & Second most preferred \\
\hline
\end{tabular}

$\mathrm{RAC}=$ risk-aversion coefficient

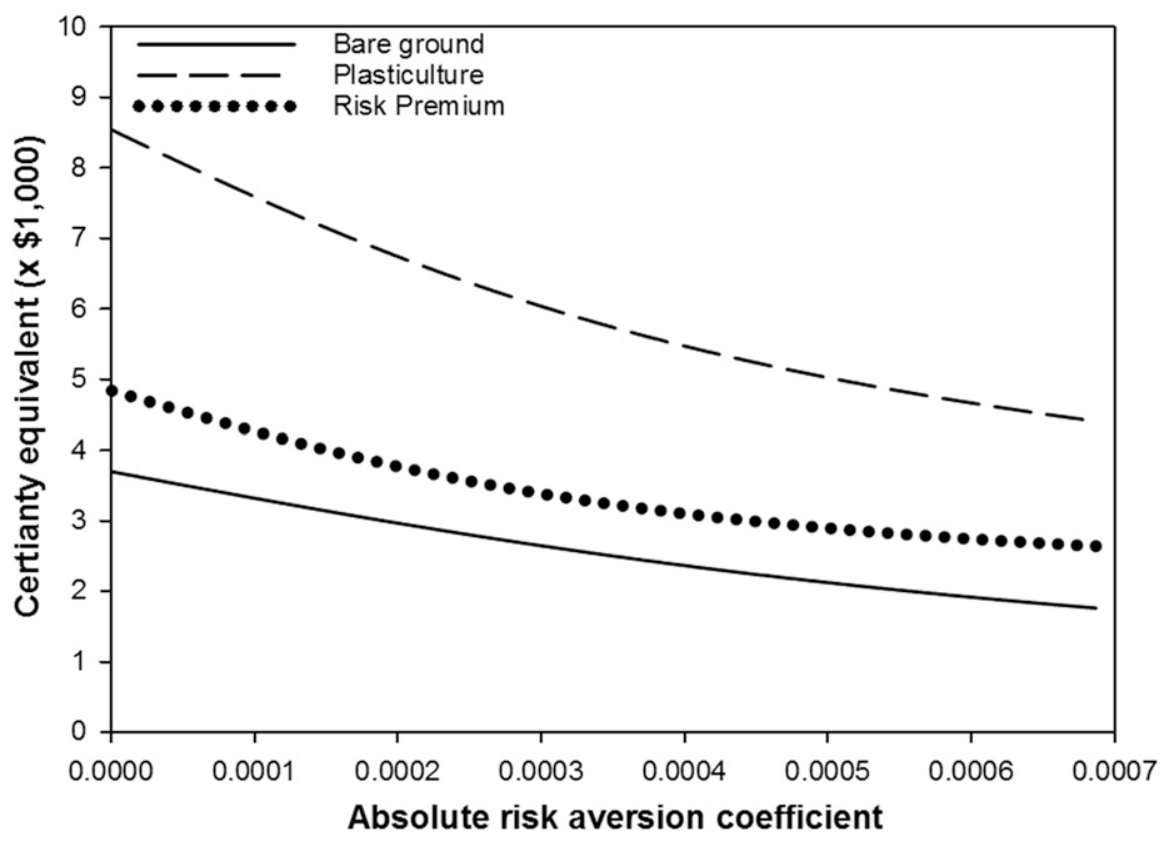

Fig. 6. Stochastic efficiency with respect to a function under a negative exponential utility function for profit of the bare ground and plasticulture cabbage production systems on a hectare basis. 


\section{Literature Cited}

Anderson, J.R. and J.L. Dillon. 1992. Risk analysis in dryland farming systems. Farming Systems Mgt. Ser. No. 2, FAO, Rome.

Barrett, C.E., L. Zotarelli, L.G. Paranhos, P. Dittmar, C.W. Fraisse, and J. VanSickle. 2018. Optimization of irrigation and N-fertilizer strategies for cabbage plasticulture system. Scientia Hort. 234:323-334.

Barrett, C.E., L. Zotarelli, L.G. Paranhos, B.S. Taylor, P. Dittmar, C.W. Fraisse, and J. VanSickle. 2015. Optimum planting configuration for high population plasticulture grown cabbage. HortScience 50:1472-1478

Barrett, C.E., L. Zotarelli, B.S. Taylor, L.G. Paranhos, and M. Warren. 2014. Converting from seepage irrigation to plasticulture for vegetable production: A case study. 15 July 2017 . < https://edis.ifas. ufl.edu/hs1246>.

Boswell, V.R. and H.A. Jones. 1941. Climate and vegetable crops, p. 373-399. In: Climate and man 1941 yearbook of agriculture. U.S. Dept. Agr., Washington, DC.

Carey, J.M. and D. Zilberman. 2002. A model of investment under uncertainty: Modern irrigation technology and emerging markets in water. Amer. J. Agr. Econ. 84:171-183.

Caswell, M., E. Lichtenberg, and D. Zilberman. 1990. The effects of pricing policies on water conservation and drainage. Amer. J. Agr. Econ. 72:883-890

Chipman, E.W. and E. Thorpe. 1979. Effect of maturity and frost on the leaf color of storage cabbage. Can. J. Plant Sci. 59:429-435.

Cordell, D., J-O. Drangert, and S. White. 2009. The story of phosphorus: Global food security and food for thought. Glob. Environ. Change 19: 292-305.

Criddle, R.S., B.N. Smith, and L.D. Hansen. 1997. A respiration based description of plant growth rate responses to temperature. Planta 201:441-445.

Csizinszky, A.A. 1987. Nutrition of cole crops with the full-bed polyethylene mulch system in westcentral Florida. J. Plant Nutr. 10:1487-1497.

Csizinszky, A.A. and D.J. Schuster. 1985. Response of cabbage to insecticide schedule, plant spacing, and fertilizer rates. J. Amer. Soc. Hort. Sci. 110:888-893.

Csizinszky, A.A. and D.J. Schuster. 1993. Impact of insecticide schedule, $\mathrm{N}$ and $\mathrm{K}$ rates, and transplant container size on cabbage yield. HortScience 28:299-302.

Csizinszky, A.A. and C.D. Stanley. 1984. Effect of trickle tubes per bed and $\mathrm{N}$ and $\mathrm{K}$ rates on spring broccoli and cabbage yields. Soil Crop Sci. Soc. Fla. Proc. 43:51-55.

de Moel, C.P. and A.P. Everaarts. 1990. Growth, development and yield of white cabbage in relation to time of planting. Acta Hort. 267:279-288.
Dukes, M.D., L. Zotarelli, and K.T. Morgan. 2010. Use of irrigation technologies for vegetable crops in Florida. HortTechnology 20:133-142.

Florida Department of Agriculture and Consumer Services (FDACS). 2014. Florida agriculture by the numbers 2013. Florida Dept. Agr. Consumer Serv., Tallahassee, FL.

Forbes, R.B., J.B. Sartain, and N.R. Usherwood. 1984. Optimum K fertilization schedule for maximizing yields of cabbage, sweetcorn, and soybeans grown in a multiple cropping sequence. Soil Crop Sci. Soc. Fla. Proc. 43:64-68.

Greenland, R.G., C.W. Lee, E.T. Holm, and L.E. Besemann. 2000. Cabbage hybrid trials in North Dakota. HortTechnology 10:806-811.

Halsey, L.H., J.F. Beeman, D.R. Hensel, W.W Deen, and V.L. Guzman. 1996. Influence of variety and spacing on yields of cabbage from a single harvest. Proc. Soil Crop Sci. Soc. Florida 79:194-201.

Hara, T. and Y. Sonoda. 1982. Cabbage-head development as affected by nitrogen and temperature. Soil Sci. Plant Nutr. 28:109-117.

Hardaker, J.B., J.W. Richardson, G. Lien, and K.D. Schumann. 2004. Stochastic efficiency analysis with risk aversion bounds: A simplified approach. Austral. J. Agr. Econ. 48:253-270.

Hochmuth, R.C., G.J. Hochmuth, and M.E. Donley. 1993. Responses of cabbage yields, head quality, and leaf nutrient status, and of second-crop squash, to poultry manure fertilization. Soil Crop Sci. Soc. Fla. Proc. 52:126-130.

Howe, T.K. and W.E. Waters. 1994. Two-year summary of cabbage cultivar yield trials. Proc. Soil Crop Sci. Soc. Fla. 107:95-99.

Kleinhenz, M.D. and A. Wszelaki. 2003. Yield and relationships among head traits in cabbage as influenced by planting date and cultivar. I. Fresh market. HortScience 38:1349-1354.

Lament, W.J. 1993. Plastic mulches for the production of vegetable crops. HortTechnology 3:35-39.

Locascio, S.J. 2005. Management of irrigation for vegetables: Past, present, and future. HortTechnology 15:482-485.

Marella, R.L. 2014. Water withdrawals, use, and trends in Florida, 2010: U.S. geological survey scientific report. U.S. Geological Survey, Reston, VA.

McKeown, A.W., S.M. Westerveld, and C.J. Bakker. 2010. Nitrogen and water requirements of fertigated cabbage in Ontario. Can. J. Plant Sci. 90:101-109.

Orzolek, M.D. 1996. Stand establishment in plasticulture systems. HortTechnology 6:181-185.

Paranhos, L.G., C.E. Barrett, L. Zotarelli, T. Borisova, R. Darnell, and K.W. Migliaccio. 2016a. Cost benefit analysis of cabbage grown using a plasticulture or seepage-bare ground production system in Florida. HortTechnology 26:699-706.
Paranhos, L.G., C.E. Barrett, L. Zotarelli, R. Darnell, K. Migliaccio, and T. Borisova. 2016b. Planting date and in-row plant spacing effects on growth and yield of cabbage under plastic mulch. Scientia Hort. 202:49-56.

Radovich, T.J.K., M.D. Kleinhenz, and N.J. Honeck. 2004. Important cabbage head traits and their relationships at five points in development. J. Veg. Crop Prod. 10:19-32.

Richardson, J.W. 2001. Simulation for applied risk management with an introduction to the software package Simetar: Simulation for Excel to analyze risk. Dept. Agr. Economics, Texas A\&M Univ., College Station, TX.

Richardson, J.W., S.L. Klose, and A.W. Gray. 2000. An applied procedure for estimating and simulating multivariate empirical (MVE) probability distributions in farm-level risk assessment and policy analysis. J. Agr. Appl. Econ. 32:299-315.

Sato, S., K.T. Morgan, M. Ozores-Hampton, and E.H. Simonne. 2009. Spatial and temporal distributions in sandy soils with seepage irrigation: I. Ammonium and nitrate. Soil Sci. Soc. Amer. J. 73:1044-1052.

Stoffella, P.J. and M.F. Fleming. 1990. Plant population influences yield variability of cabbage. J. Amer. Soc. Hort. Sci. 115:708-711.

Strandberg, J.O. and J.M. White. 1979. Estimating fresh market cabbage maturity dates in a winter production area. Proc. Soil Crop Sci. Soc. Florida 92:96-99.

Sundstrom, F.J. and R.N. Story. 1984. Cultivar and growing season effects on cabbage head development and weight loss during storage. HortScience 19:589-590.

U.S. Department of Agriculture. 2015. National agricultural statistics service quickstats data portal. 15 July 2017. <http://www.nass.usda. gov/Quick_Stats/>.

VanSickle, J.J. 2008. Cabbage: Estimated production costs in the Hastings area. 13 Oct. 2015. <http://fred.ifas.ufl.edu/pdf/iatpc/files/ HastingsCabbage09.pdf $>$.

Warland, J., A.W. McKeown, and M.R. McDonald 2006. Impact of high air temperatures on Brassicaceae crops in southern Ontario. Can. J. Plant Sci. 86:1209-1215.

Wittwer, S.H. 1993. World-wide use of plastics in horticultural production. HortTechnology 3:6-19.

White, J.M. and R.B. Forbes. 1976. Effect of spacing and fertilizer rates on cabbage yield and head weight. Proc. Soil Crop Sci. Soc. Fla. 89:118-120.

Wszelaki, A. and M.D. Kleinhenz. 2003. Yield and relationships among head traits in cabbage as influenced by planting date and cultivar. II. Processing. HortScience 38:13551359. 